\title{
EFFICACY OF HELIUM - OXYGEN MIXTURES IN THE MANAGEMENT OF SEVERE VIRAL AND POST-INTUBATION CROUP
}

\author{
Peter G. Duncan
}

UPPER AIRWAY OBSTRUCTION due to viral or post-intubation croup is usually mild in children and improves with symptomatic measures only. Occasionally, progressive airway obstruction requiring excessive work for breathing leads to exhaustion of the child and respiratory failure. Such cases require prompt intervention either with an artificial airway or the use of racemic epinephrine as a topical vasoconstrictor ${ }^{1,2}$ to prevent a fatality. Delivered either by intermittent positive pressure breathing (IPPB) or face mask, ${ }^{3}$ racemic epinephrine rapidly reduces the work of breathing, improves clearance of secretions, and settles the child. Repeated as necessary, such therapy will usually sustain the child until the self-limited croup runs its natural course. However, in some children, racemic epinephrine is of limited benefit or contraindicated for technical or medical reasons (example: Tetrology of Fallot).

The reported incidence of croup requiring artificial airways is variable but may be as high as 6.5 per cent of croup patients. ${ }^{4}$ In these instances the use of helium rather than nitrogen as a carrier gas for oxygen was advocated as long ago as 1936. 5 This paper presents our experience in seven patients with severe croup in whom artificial airways were avoided by the use of heliumoxygen mixtures, and reviews the rationale and limitation of this treatment modality.

\section{Methods and Materials}

This series represents all cases of severe airway obstruction due to croup presenting during a two-year period ending July 1978. Upon referral to the Intensive Care Service for airway management the patients were scored by an independent observer according to the system reported by Downes. ${ }^{6}$ The scores are based on the quality of breath sounds, degree of stridor, cough, retractions and presence or absence of cyanosis. According to the Philadephia series a score

Peter G. Duncan, M.D. Assistant Professor of Anaesthesia \& Paediatrics. Director, Paediatric Intensive Care Unit, Health Sciences Centre (Children's), 700 William Ave., Winnipeg, Manitoba, R3E 0Z3.

Canad. Anaesth. Soc. J., vol. 26, no. 3, May 1979 greater than four indicates severe airway obstruction, while a score over seven usually indicates the need for an artificial airway. The score thus represents an objective measure of collected clinical observations.

After initial scoring and assurances that optimal conservative management had been employed, the patients were placed into an atmosphere of helium 70 to 80 per cent with oxygen, administered by either reservoir mask or headbox depending on the patient's size. Helium mixtures were obtained from commercially available tanks ( 80 per cent helium, 20 per cent oxygen) and administered at a non-rebreathing flow by a calibrated regulator. Further oxygen was entrained by a separate regulator to maintain the $\mathrm{F}_{\mathrm{I}_{2}}$ required by the patients to maintain oxygenation. All conservative therapy was continued during the helium trial. $\mathrm{Fl}_{\mathrm{O}_{z}}$, heart rate and respiratory status were monitored continuously in the Intensive Care Unit. Blood gases were measured in capillary blood as necessary to follow the patient's course. Croup scoring was repeated 15 minutes after stabilization in the new ambient environment.

The clinical status of the seven patients is summarized in Table I. Discussion of individual case histories follows:

\section{Patiem 1}

A full-term newborn female weighing $3.89 \mathrm{~kg}$ presented at 12 hours of age with a $9 \times 6 \mathrm{~cm}$ semisolid mass in the neck causing obstruction and deviation of the trachea to the right. Her trachea had been intubated with some difficulty at birth because of marked respiratory distress. Preoperative evaluation revealed normal thyroid, parathyroid, and oesophageal function. At three days of age a teratoma extending from the left posterior triangle to the right sternomastoid was removed. The patient remained intubated for four days to allow operative oedema to subside, and the trachea was then extubated under steroid coverage. Racemic epinephrine was given by IPPB but marked stridor necessitated reintubation. At laryngoscopy the larynx was swollen and the left vocal cord was paralyzed. 
TABLE I

SUMmary of CASE Histories

The clinical histories of the seven cases reported as assessed by an independent observer before and after institution of helium therapy. The improvement in croup score was significantly different by the Student's paired $t$-test. Respiratory rate was not altered. PIC $=$ Post-intubation croup, $L T B=$ Infectious laryngotracheobronchitis

\begin{tabular}{|c|c|c|c|c|c|c|c|}
\hline \multirow[b]{2}{*}{ Case } & \multirow[b]{2}{*}{ Age } & \multirow[b]{2}{*}{$\begin{array}{c}\text { Respiratory } \\
\text { diagnosis }\end{array}$} & \multirow[b]{2}{*}{$\begin{array}{l}\text { Associated } \\
\text { diagnosis }\end{array}$} & \multicolumn{2}{|c|}{$\begin{array}{l}\text { Group } \\
\text { score }\end{array}$} & \multicolumn{2}{|c|}{$\begin{array}{l}\text { Respiratory } \\
\text { rate }\end{array}$} \\
\hline & & & & $\begin{array}{l}\text { In } \\
\text { air }\end{array}$ & $\underset{\text { helium }}{\text { In }}$ & $\begin{array}{l}\text { In } \\
\text { air }\end{array}$ & $\begin{array}{c}\text { In } \\
\text { helium }\end{array}$ \\
\hline 1 & Newborn & P.I.C. & $\begin{array}{l}\text { Left cord } \\
\text { paralysis } \\
\text { (surgical) }\end{array}$ & 9 & 4 & 48 & 44 \\
\hline 2 & 6 months & P.I.C. & $\begin{array}{l}\text { Cleft lip } \\
\text { \& palate } \\
\text { (repaired) }\end{array}$ & 8 & 4 & 52 & 52 \\
\hline 3 & 11 months & P.I.C. & $\begin{array}{l}\text { Bronchoscopy } \\
\text { for possible } \\
\text { foreign body }\end{array}$ & 7 & 4 & 40 & 40 \\
\hline 4 & 7 months & L.T.B. & - & 8 & 4 & 44 & 45 \\
\hline 5 & 3 years & L.T.B. & $\begin{array}{l}\text { Tetrology } \\
\text { of Fallot }\end{array}$ & 9 & 5 & 56 & 38 \\
\hline 6 & Newborn & P.1.C. & $\begin{array}{l}\text { Pneumonia } \\
\text { patent ductus } \\
\text { arteriosus } \\
\text { left cord } \\
\text { paralysis }\end{array}$ & 6 & 3 & 50 & 44 \\
\hline \multirow[t]{2}{*}{7} & 3 months & P.I.C. & $\begin{array}{l}\text { Pierre-Robin } \\
\text { syndrome }\end{array}$ & 8 & 3 & 72 & 50 \\
\hline & & $\begin{array}{l}\text { Mean } \\
\text { S.E.M. } \\
\text { P }\end{array}$ & & $\begin{array}{r}7.9 \\
\pm 0.4\end{array}$ & $\begin{array}{r}3.9 \\
\pm 0.3 \\
.001\end{array}$ & $\begin{array}{r}51.7 \\
\pm 7.0\end{array}$ & $\begin{array}{r}44.7 \\
+6.7 \\
0.10\end{array}$ \\
\hline
\end{tabular}

Two further attempts at extubation at 24-hour intervals were equally unsuccessful.

Before proceeding to tracheostomy a trial of extubation and helium/oxygen therapy $(80 / 20)$ was attempted. Upon extubation the baby again had stridor, but improved immediately in the $\mathbf{8 0}$ per cent helium head-box. She remained only mildly distressed for the next 24 hours, after which she was removed to room air with moderate worsening. She was discharged on day 12 with minimal hoarseness and a left vocal cord paralysis.

\section{Patient 2}

A six-month-old male with bilateral cleft lip and palate, polycystic kidneys, hypospadias and atrial septal defect had an uncomplicated repair of the lip under general anaesthesia. Tracheal intubation was atraumatic. He was extubated awake in satisfactory condition but at two hours became congested, cyanotic and began indraw- ing. Racemic epinephrine by face mask, steroids, and gentle suction resulted in only mild improvement. Moreover, supraventricular trachycardia (rate $220 / \mathrm{min}$ ) limited the frequency and continued use of vaponephrine therapy. He was therefore placed in 70 per cent helium with 30 per cent oxygen, with improvement of indrawing. Gradual improvement continued over 48 hours and helium therapy was discontinued successfully at that time.

\section{Patient 3}

An 11-month-old male was admitted with a 24-hour history of stridor unresponsive to mist, racemic epinephrine and ampicillin. Physical examination revealed marked indrawing (subcostal, sternal, and supraclavicular), cyanosis. and absence of air entry over the left chest. Lateral neck and chest radiographs showed mild subglottic oedema and total opacification of the left lung. Suspecting an aspirated foreign body, 
he was taken to the operating room where bronchoscopy under general anaesthesia removed inspissated purulent secretions from the left main stem bronchus. Subglottic oedema was minimal and aeration of the left chest improved dramatically. However, upon withdrawal of the bron. choscope laryngospasm necessitated transient re-intubation. One hour after bronchoscopy he again had stridor and severe indrawing, with little improvement from racemic epinephrine by face mask or IPPB. Repeated laryngoscopy revealed markedly swollen false cords and arytenoids, necessitating re-intubation for relief of respiratory distress. Steroid administration was started. Four hours later he extubated himself and began to indraw severely. Epinephrine again did not help. He was therefore started breathing helium and oxygen 80:20 by reservoir mask with immediate relief. Over the ensuing four days continuation of helium and oxygen with intermittent racemic epinephrine kept him rested until gradually all therapy could be withdrawn.

\section{Patient 4}

A seven-month-old male was admitted with a 24-hour history of cough and respiratory distress. On examination he had marked indrawing with audible inspiratory stridor and wheezing. Radiographs revealed marked subglottic oedema and normal lung fields. Over the ensuing 36 hours therapy with mist, intravenous fluids, oxygen, and racemic epinephrine as often as every 20 minutes failed to bring sufficient relief. As he was clinically becoming exhausted he was tried in 70 per cent helium with 30 per cent oxygen administered by headbox with marked reduction in stridor, enabling him to sleep while maintaining adequate blood gases. After 36 hours helium was discontinued with no difficulty.

\section{Patient 5}

A three-year-old girl with known Tetrology of Fallot was admitted with a two-day history of stridor, fever, indrawing, and tachypnoea. Radiographs showed collapse of the left lower lobe as well as marked subglottic narrowing. Therapy commenced with mist, oxygen, physiotheraphy, hydration, and amoxicillin in addition to her maintenance digitalis and furosemide. Progression of the stridor and indrawing with worsening cyanosis led to a trial of helium 60 per cent with oxygen 40 per cent by mask, which resulted in rapid improvement. Three attempts to withdraw the helium necessitated its readministration to relieve recurrence of severe re- spiratory distress. After 24 hours the helium was successfully withdrawn and she was discharged at five days.

\section{Patient 6}

A 38-week gestation female weighing $2860 \mathrm{gm}$ presented at three weeks of age with bilateral bronchopneumonia and frequent apnoeic spells. Intubation and positive pressure ventilation were needed for four days. The appearance of a murmur and clinical signs of congestive cardiac failure suggested a patent ductus arteriosus and the child was digitalized. Upon extubation severe stridor refractory to racemic epinephrine necessitated re-intubation. At laryngoscopy the left vocal cord was immobile and marked swelling of the arytenoids and subglottic structures was seen. Thirty hours later the child was again extubated with recurrence of the stridor. She was then placed in 70 per cent helium with 30 per cent oxygen with relief of symptoms. At 18 and 24 hours withdrawal of therapy was attempted and failed, but after 30 hours the helium was successfully discontinued with no further difficulty.

\section{Patient 7}

A two-month-old male with multiple congenital anomalies including micrognathism, macroglossia, low ears, multiple hernias and growth retardation underwent elective repair of left talipes equinovarus. Local anaesthesia was used because multiple attempts at tracheal intubation were unsuccessful because the larynx could not be visualized. Twenty-four hours postoperatively he had a temperature of $40.2^{\circ} \mathrm{C}$, became tachypnoeic, was grunting and had stridor and severe indrawing of the sternal, subcostal and supraclavicular areas, Radiographs showed subglottic oedema and a mild right middle lobe infiltrate. Racemic epinephrine therapy was minimally successful, so a trial of helium 80 per cent with oxygen 20 per cent was given in the isolette. Rapid settling ensued, and helium was easily withdrawn 12 hours later.

\section{Results}

The patients in this series moved from a mean croup score of 7.9 to $\mathbf{3 . 9}$ upon institution of helium therapy (Table I), a statistically significant change by the Student's paired t-test. No other patients required tracheal intubation for airway obstruction due to uncomplicated croup over the two years during which these cases were collected. Respiratory rate was unchanged by 


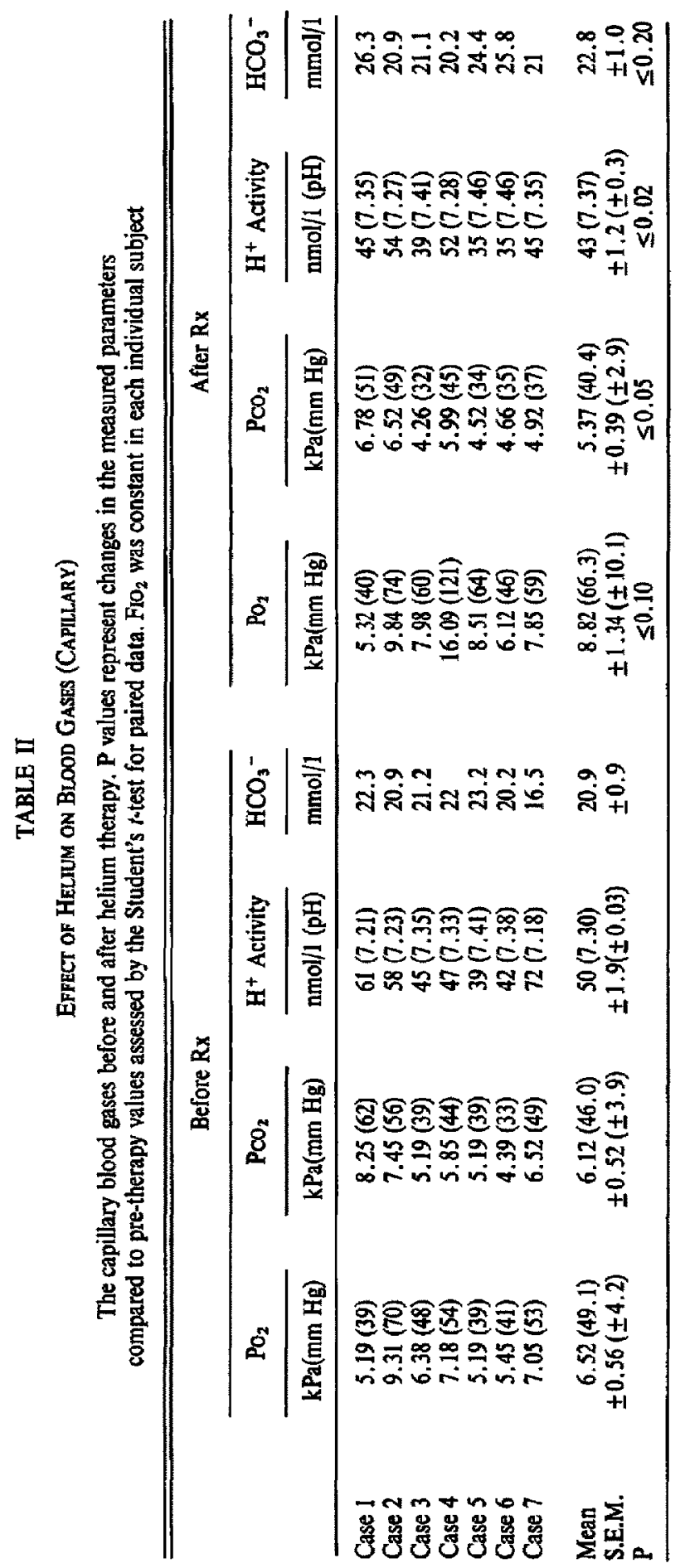


TABLE III

Densities and Relative Gas flow Rates of Oxygen, Air and Helium

Densities and relative gas flow rates of air, oxygen, and helium as reported in MacIntosh. ${ }^{\text {? }}$ In order to significantly influence gas flow rates helium must be administered in concentrations greater than 60 per cent

\begin{tabular}{|c|c|c|c|c|c|}
\hline & $\%$ & Density & $\sqrt{\text { Density }}$ & $\frac{1}{\sqrt{\text { Density }}}$ & $\begin{array}{l}\text { Relative gas flow rate } \\
\text { (air assigned an arbitrary value of } 1.00 \text { ) }\end{array}$ \\
\hline $\begin{array}{l}\text { Oxygen } \\
\text { Air } \\
\text { Helium } \\
\text { He-oxygen } \\
\text { He-oxygen } \\
\text { He-oxygen }\end{array}$ & $\begin{array}{c}100 \\
100 \\
100 \\
20 / 80 \\
60 / 40 \\
80 / 20\end{array}$ & $\begin{array}{l}1.429 \\
1.293 \\
0.179 \\
1.178 \\
0.678 \\
0.429\end{array}$ & $\begin{array}{l}1.182 \\
1.135 \\
0.423 \\
1.085 \\
0.823 \\
0.655\end{array}$ & $\begin{array}{l}0.846 \\
0.881 \\
2.364 \\
0.922 \\
1.215 \\
1.527\end{array}$ & $\begin{array}{l}0.96 \\
1.00 \\
2.68 \\
1.048 \\
1.381 \\
1.73\end{array}$ \\
\hline
\end{tabular}

helium administration. Capillary blood gas analysis reflected minimal changes due to helium therapy (Table II) with all but one case demonstrating a reduction in $\mathrm{PCO}_{2}$ and normalization of $\mathrm{pH}$. While capillary $\mathrm{PO}_{2}$ improved in all cases (constant $\mathrm{FI}_{\mathrm{O}_{2}}$ ), the significance of the change is questionable in view of improved tissue perfusion at normal $\mathrm{pH}$, and lack of validity of capillary $\mathrm{PO}_{2}$ at high arterial tensions. In no patient did oxygenation decrease.

\section{Discussion}

The benefit of helium to the seven paediatric patients included in this report was dramatic as assessed clinically and by blood gases. Although these patients constituted a group expected to require artificial airways due to exhaustion from excessive work of breathing, ${ }^{6}$ all had resolution of their symptoms with time obtained while breathing the helium mixture. Settling of the patient (often falling to sleep) reflected subjective improvement with helium therapy and correlated with the improvement in croup scores, acid-base status, and gas exchange.

A more objective demonstration of benefit, such as oesophageal manometry to measure respiratory work, would be difficult due to the labile nature of airways obstruction in small children. In addition, the testing itself may precipitate complete obstruction in the small child with critical upper airway narrowing. Laslly, patients' objections to such procedures may be sufficiently vigorous to invalidate results. We have found that the clinical croup score, while designed primarily for assessment of infectious laryngotracheobronchitis, has been useful for the objective evaluation of post-intubation croup as well.

The rationale for helium therapy has been known and suggested as treatment for airway narrowing for many years." Fanning's law states that gas flow through an orifice is inversely proportional to the square root of its density. ${ }^{7}$ The low density helium-oxygen mixture (Table III) promoles better gas flow through a narrow orifice, therefore reducing the pressure (and work) required to exchange a tidal breath. Helium-oxygen has been used successfully in adult airway stenosis ${ }^{8}$ as well as to aid the weaning of children from mechanical ventilation. ${ }^{9}$ Experimental work ${ }^{10}$ has substantiated the beneficial effect of helium in conditions associated with turbulent airflow in the upper airway and trachea, but has failed to demonstrate improved flow characteristics in obstruction of smaller airways where flow is laminar and thet efore dependent on viscosity rather than density. Thus it is reasonable to expect improvement in the work of breathing in croup but not in conditions such as bronchiolitis or asthma. While most of these patients suffered from post-intubation croup which is confined to the upper trachea more than infectious laryngotracheobronchitis, its benefit in the latter entity is suggested by cases 4 and 5 .

Helium therapy may theoretically be of greater value in the small child than in the adult for reasons illustrated in Figure 1. Normally the extrathoracic trachea narrows during inspiration due to the sub-atmospheric pressure in the lumen compared to the outside. In conditions of upper airway narrowing there is increased subatmospheric pleural pressure created during inspiration to overcome resistive forces. The greater increase in negative pressure will be transmitted to the extrathoracic trachea (which is below the narrowing) and result in a tendency to collapse the pliable trachea of the small child. The reduced work of breathing (and hence re- 


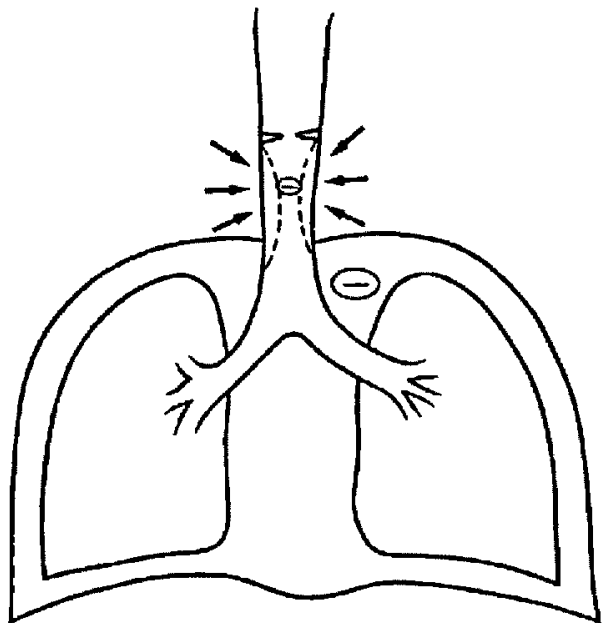

Figure 1 Schematic representation of the dynamics of extrathoracic airway narrowing in children with pliable tracheas during inspiration. The increased subatmospheric pleural pressure required to overcome aifflow resistance is transmitted to the subglottic area, resulting in an increased pressure gradient across the trachea (relative to outside atmospheric pressure) tending to further compromise lumen diameters.

duced negative pressure needed for ventilation) associated with helium breathing will minimize this tendency of the trachea to collapse. Helium may thereby preserve airway diameter in the presence of extrathoracic airway narrowing such as seen in croup.

Helium therapy in croup must, however, be used with reservation and caution. In order to affect a significant change in gas density, helium must be administered in as high a concentration as possible. Since children with severe croup are usually hypoxaemic," oxygen concentrations must be carefully monitored to avoid excessive reductions in $\mathrm{Fl}_{\mathrm{O}_{2}}$. While helium therapy increases the tolerance to hypoxia, ${ }^{12}$ the limit to inspired oxygen concentration of $\mathbf{4 0}$ per cent (i.e. 60 per cent helium to reduce gas density) implies that helium therapy is relatively contra-indicated when hypoxaemic pulmonary disease (example: bronchopneumonia) complicates croup and requires a high $\mathrm{FI}_{\mathrm{O}_{2}}$. Thirdly, since helium therapy does not cure the entity but simply "buys time" for spontaneous resolution of the problem, it must be used only under close observation. Fourthly, the need for high concentrations of a relatively expensive gas necessitates efficient methods of administration. We have found small head boxes or reservoir masks to be satisfactory in the application of this mixture to these chil- dren. In spite of these problems, however, helium-oxygen therapy should be considered as a rational alternative to nasotracheal intubation or tracheostomy in children with severe viral or post-intubation croup.

\section{SUMMARY}

An appreciable number of children with viral or post-intubation croup progress to respiratory failure necessitating an artificial airway. We report seven such patients with critical airway narrowing in whom we reduced the work of breathing by deploying helium rather than air as a carrier gas for oxygen. Assessment of patients by a croup-scoring system and blood gas analysis suggests helium-oxygen mixtures to be a useful alternative to intervention with tracheostomy or tracheal intubation. The rationale and limitations of this treatment are discussed.

\section{RÉSUMÉ}

Un certain nombre d'enfants présentant un faux-croup d'origine virale ou secondaire à une intubation, évoluent vers une insuffisance respiratoire nécessitant une réintubation ou une trachéostomie. Nous rapportons sept de ces cas avec atteinte grave où l'on a pu réduire le travail de la respiration avec l'emploi d'un mélange hélium-oxygène au lieu d'un mélange airoxygène. L'évolution de ces enfants évaluée au moyen de l'échelle de Downes (Croup Score) et de gazométries, a démontré que le mélange hélium-oxygène est une mesure utile permettant souvent d'éviter une réintubation ou une trachéostomie. La justification et les limites de cette thérapie sont discutées.

\section{ACKNOWLEDGEMENTS}

The co-operation of the physicians and surgeons of the Health Sciences Centre (Children's) who referred their patients to the Intensive Care Service is gratefully appreciated.

\section{REFERENCES}

1. Jordon, W.A., Graves, C.L., \& Elwyn, R.A. New therapy for postintubation laryngeal edema and tracheitis in children. J.A.M.A. 212: 585-588 (1970).

2. ADAIR, J.C., RiNG, W.H., JoRdAN, W.S., \& ELwYN, R.A. Ten-year experience with IPPB in the treatment of acute laryngotracheobronchitis. Anes, and Anal, (Clev,), 50:649-654 (1971)

3. OH, T.H. \& DOWNES, J.J. Comparison of IPPB and 
powered nebulizer to administer racemic epinephrine in croup. Abstracts of Scientific Meetings. American Society of Anesthesiologists Annual Meeting, New Orleans (1977).

4. SCHUlLER, D.E. \& BirCK, H.G. The safety of intubation in croup and epiglottitis: An eight-year follow-up. Laryngoscope: $85: 33$ (1975)

5. BARACH, A.1. The therapentic use of helium. J.A.M.A. 107: 1273-1279 (1936).

6. Downes, J.J. \& Raphaely, R.C. Pediatric intensive care. Anesthesiology 43: 238-250 (1975).

7. Macintosh, R., Mushin, W.W., \& Epstien, H.G. Helium-oxygen mixture. In: Physics for Anesthetists. Second edition, Oxford Blackwell, pp. 192-195, 250-251 (1958).

8. Lee, T.S., Ohmura, A., Wong, K.C., \& Hodges,
M.R. Helium-oxygen in treatment of upper airway obstruction. Anesthesiology 45: 678-681 (1976)

9. Tatsumo, K., Omai, Y., \& Konno, S. Therapeutic use of Helium-Oxygen mixture in CPAP for early weaning from mechanical ventilation after cardiovascular surgery in infants. J. Thor. Cardiovasc. Surg. 72: 119-122 (1976).

10. Barnett, T.B. Effects of helium and oxygen mixtures on pulmonary mechanics during airway abstruction. J. Appl. Physiol. 22(4) 707-713 (1967).

11. NewTH, C.J.L. LeVISON, H. \& BRYAN, A.C. The Respiratory status of children with croup. Journal of Pediatrics 81: 1068-1073 (1972).

12. Altland, P.D., Brubach, H.F., \& Parker, M.G. Effects of inert gases on tolerance of rats to hypoxia. J. Appl. Physiol. 24(6): 778-781 (1968). 